Abstract\#: A-2021-RE10008

Tao Xingzhi Study Association of China \& Huzhou University

May 28-30, 2021, Huzhou, Zhejiang Province, China

\title{
The Design and Research of the Projected Problem: Solving Teaching Research Activities
}

\section{Xiumei Dai, ${ }^{1}$ Liangbin $\mathbf{Y i}^{2}$}

Affiliation: 1. Teacher Education College of Xiacheng District, Hangzhou 310000, Zhejiang, China. 2. Hangzhou Jianggan District Education Development Research Institute, Hangzhou 310000, Zhejiang, China.

Address: 1. Xiacheng District, Hangzhou 310000, Zhejiang, China.

2. Jianggan District, Hangzhou 310000, Zhejiang, China.

Correspondence to: Xiumei Dai, E-mail: $505330821 @ q q . c o m$

DOI: https://doi.org/10.15354/sief.21.s1.ab037

The authors declare no competing interest.

Promoting teachers' professional development has become the overall goal of teachers' training in the new era. In this article, the researches on classroom, teaching material, and examination assignment were considered as the carriers, taking the interactive process Plan-Action-Observation-Reflection as the path, so as to contribute to the project features, including the task collection and selection, materials sorting, joint R\&D, and problem-solving. Through the reform of traditional teaching activities, the article particularly explored and analyzed the intention, procedure, and content of innovative Mathematics teaching research activity through the projected teaching, and researching model. It is important to pay attention to the combination of theory and practice, education and scientific research, teacher research and expert guidance, so as to enhance the teachers' professional abilities to solve the teaching problems and promote the regional Mathematics teaching activities to a deeper level.

Keywords

Problem-Solving, Projectization, Teaching and Research Activities, Strategy

Science Insights Education Frontiers, 2021 September 13; Vol. 10, Suppl. 1, pp.7.

(C) 2021 Insights Publisher. All rights reserved.

(C) (i) Creative Commons Non Commercial CC BY-NC: This article is distributed under the terms of the Creative Commons Attribution-NonCommercial 4.0 License which permits non-commercial use, reproduction and distribution of the work without further permission provided the original work is attributed by the Insights Publisher. 